University of Nebraska - Lincoln

DigitalCommons@University of Nebraska - Lincoln

\title{
Behavioral Basis of Second Intermediate Host Specificity among Four Species of Haematoloechus (Digenea: Haematoloechidae)
}

\section{Scott D. Snyder}

University of Nebraska at Omaha, sdsnyder@mail.unomaha.edu

John J. Janovy Jr.

University of Nebraska - Lincoln, jjanovy1@unl.edu

Snyder, Scott D. and Janovy, John J. Jr., "Behavioral Basis of Second Intermediate Host Specificity among Four Species of Haematoloechus (Digenea: Haematoloechidae)" (1996). John Janovy Publications. 27. https://digitalcommons.unl.edu/bioscijanovy/27 


\title{
BEHAVIORAL BASIS OF SECOND INTERMEDIATE HOST SPECIFICITY AMONG FOUR SPECIES OF HAEMATOLOECHUS (DIGENEA: HAEMATOLOECHIDAE)
}

\author{
Scott D. Snyder and J. Janovy, Jr. \\ School of Biological Sciences, University of Nebraska-Lincoln, Lincoln, Nebraska 68588-0118
}

\begin{abstract}
Cercarial behavior patterns were examined in 4 species of frog lung flukes (Haematoloechus spp.). Cercariae of Haematoloechus complexus, Haematoloechus medioplexus, Haematoloechus longiplexus, and Haematoloechus varioplexus were exposed to 3 species of experimental arthropods and an inanimate control. The number of cercariae attached to an experimental host at $5 \mathrm{~min}$ postexposure was recorded. Haematoloechus longiplexus and $\mathrm{H}$. complexus cercariae attached to experimental hosts at higher rates than cercariae of $H$. medioplexus and $H$. varioplexus. Cercariae of $H$. longiplexus attached to experimental hosts in approximately the same numbers as $H$. complexus, but $H$. longiplexus penetrated only damselfly naiads, and only at the base of the zygopteran caudal gills. Cercariae of $H$. complexus, a second intermediate host generalist, were able to penetrate and enter several arthropod species at the intersegmental membranes. Haematoloechus medioplexus and $H$. varioplexus are restricted to development in dragonfly naiads and cercariae rarely attached to and never penetrated experimental hosts. These behavioral patterns dictate the range of hosts suitable for metacercarial development of $H$. complexus, $H$. longiplexus, $H$. medioplexus, and $H$. varioplexus. The evolution of disparate patterns of behavior among the cercariae of these 4 congeners has directly affected subsequent patterns of transmission to the definitive host.
\end{abstract}

Host specificity has traditionally been viewed as the result of a complex interaction between parasites and potential hosts. Investigations of this interaction have often focused on the biochemical and environmental requirements of the parasite. For example, urea has been implicated as a component essential to the maintenance of osmotic balance in the cestodes of elasmobranchs (Read et al., 1959). Other investigations concerning the nature of host specificity have examined the degree and effectiveness of immune response by the host. Adema et al. (1994) found that the hemocytes of snails susceptible to infection with larval Echinostoma paraensei suffered impaired function in the presence of this parasite. The hemocytes of resistant snails functioned normally.

The role of parasite behavior in directly determining host specificity generally has been ignored, although many studies have examined the role of behavior in increasing the probability that parasite infective stages will come into contact with a potential host. Examples of the increased risk of predation of acanthocephalan-infected amphipods are well known, e.g., Bethel and Holmes (1977). Similarly a myriad of studies have demonstrated that the miracidia and cercariae of many trematode species exhibit behaviors that bring them into the preferred habitat of a potential host. Other cercariae respond directly to stimuli created by potential hosts. For example, Cryptocotyle lingua cercariae significantly increase activity in response to a passing shadow, thus enhancing transmission to excised pectoral fins designed to mimic a fish host (Rea and Irwin, 1991, 1992) and Schistosoma mansoni and Schistosoma haematobium cercariae respond to different chemical and thermal host cues and display different swimming behaviors (Haas et al., 1994). These differences were considered to represent adaptations to the disparate environmental conditions under which these 2 species of schistosome cercariae encounter their hosts.

These examples demonstrate the importance of behavior in successful parasite transmission. However, they do not attempt to demonstrate that parasite behavior itself may determine host

Received 26 June 1995; revised 25 September 1995; accepted 25 September 1995. suitability. The present study examined the influence of cercarial behavior on the second intermediate hosts available to 4 species of frog lung flukes (Haematoloechus spp.).

Haematoloechus spp. are considered to develop typically in odonate hosts (Olsen, 1967). Reports of non-odonate hosts are rare and were limited to dipteran and plecopteran larvae (van Theil, 1930; Dollfus et al., 1960; Combes, 1968). However, Snyder and Janovy (1994) reported the development of Haematoloechus complexus in 2 non-odonate insects and 3 crustacean species as well as in odonates. In the same study, the development of Haematoloechus medioplexus was restricted to anisopteran (dragonfly) naiads. Preliminary investigations implicated cercarial behavior as a causative factor in determining second intermediate host specificity. The present study demonstrates that different cercarial behavioral patterns among 4 species of Haematoloechus directly determine second intermediate host specificity. Thus, host specificity among metacercariae of Haematoloechus species is, at least in part, a function of evolutionary divergence in behavioral patterns rather than present-day biochemical and immunological interactions between parasite and host.

\section{MATERIALS AND METHODS}

\section{Host and parasite maintenance}

Adult flukes were dissected from wild-caught frogs and identified according to Kennedy (1981). With the exception of $H$. medioplexus, adult parasites were retrieved from several frog populations in Nebraska. Haematoloechus medioplexus adults were retrieved from frogs of a single population. Snails used were laboratory reared and infected using the techniques of Snyder and Janovy (1994). The planorbid snail Gyraulus parvus served as first intermediate host to Haematoloechus longiplexus, H. medioplexus, and Haematoloechus varioplexus. Haematoloechus complexus developed in the physid snails Physella virgata, Physella gyrina, and Physella heterostropha.

Asellus intermedius were reared in the laboratory. All other arthropods used in the host specificity experiments were obtained from natural populations. To ensure that the animals from nature were not naturally infected, subsamples of 10 individuals per species were dissected and examined for metacercariae at the time of experimental exposure $\left(T_{0}\right.$ control). An additional subsample of 10 individuals per species remained unexposed and were held for the duration of the experiment. These ending time $\left(T_{t}\right)$ control groups were dissected and examined for 
metacercariae to corroborate the absence of natural infections. All arthropods used in the cercarial behavior experiments were collected from natural populations with the exception of $A$. intermedius. Previous studies had established that these natural populations were free of $\mathrm{Hae}$ matoloechus infection (S. D. Snyder, unpubl. obs.).

\section{Host specificity of H. longiplexus}

and $\boldsymbol{H}$. varioplexus

The second intermediate host specificity of $H$. complexus and $H$. medioplexus has been previously determined (Snyder and Janovy, 1994). In order to make comparisons between all species used in the present study, the second intermediate host specificity of $H$. longiplexus and $H$. varioplexus was examined. Specificity was tested for damselfly naiads (Ischnura verticalis), dragonfly naiads (Libellula sp.), ephemeropteran naiads (Baetis sp.), and aquatic isopods ( $A$. intermedius). Ten individuals of each host species were used. Arthropods were placed individually in a 70-ml plastic jar filled with approximately $35 \mathrm{ml}$ of aged tap water and a snail known to be shedding cercariae. Arthropods were exposed for 22-24 hr, removed, and isolated in a snail-free jar or placed in an aerated container with other exposed conspecifics. Arthropods were necropsied 7-10 days postexposure and examined for metacercariae. Two individuals of each arthropod species were exposed to cercariae of H. complexus, a second intermediate host generalist (Snyder and Janovy, 1994). This experimental group served as a control for strain resistance to Haematolechus spp. infection in experimental arthropod populations.

\section{Observations of cercarial behavior}

Observations of cercarial behavior were made by placing several cercariae of 1 parasite species in a $0.75-\mathrm{mm}$ deep depression slide with aged tap water and an arthropod. Cercarial behavior was observed for periods up to $90 \mathrm{~min}$ with the aid of a compound microscope connected to a camera and video cassette recorder.

\section{Cercarial attachment experiments}

Two separate experiments were conducted to determine the role of cercarial behavior in second intermediate host specificity. In the first set of experiments, potential hosts were exposed to cercariae of $H$. complexus, $H$. medioplexus, and $H$. varioplexus. Experimental arthropods consisted of damselfly naiads (I. verticalis), dragonfly naiads (Libellula julia), and freshwater isopods (A. intermedius). To assess the possibility that cercariae respond to any animate or inanimate object in the water, separate attachment trials were conducted using a $1.0-\mathrm{cm}$ $\times 0.2-\mathrm{cm}$ piece of silicone rubber in place of the arthropod host.

Individual experimental arthropods or controls were placed in a 0.75 $\mathrm{mm}$ deep depression slide with aged tap water and 40 cercariae. The slide was sealed with a coverslip and examined under light microscopy 5 min postexposure. The number of cercariae crawling on, attached to, or penetrating the experimental subject was recorded. Cercariae displaying any of these behaviors were recorded as attached. The protocol was replicated 5 times for each experimental host/parasite and control/ parasite combination.

The 5-min examination time was chosen to provide cercariae time to acclimate without allowing mortality to decrease the pool of cercariae present. Observations showed that cercariae of attaching species immediately began to attach to arthropods upon exposure. But, after approximately $10 \mathrm{~min}$, dead cercariae were observed, apparent victims of deteriorating environmental quality or puncture on arthropod cuticular spines.

The second set of experiments examined the attachment behavior of $H$. longiplexus and $H$. complexus. This set of experiments was necessary because cercariae of $H$. longiplexus were not available in the laboratory when the first attachment experiments were conducted. Cercariae of $H$. complexus were used as a positive control to ensure that results were comparable to the first set of experiments. The experimental protocol was identical to the first set of experiments, excepting that an unknown species of the dragonfly genus Libellula was used in place of $L$. julia.

\section{Population structure of Haematoloechus spp.}

A field survey was conducted to determine the influence of cercarial behavior on the population structure of $H$. complexus and $H$. medioplexus within second intermediate hosts. Arthropods were collected in
TABLE I. Infection rates of experimental hosts exposed to cercariae of Haematoloechus longiplexus or Haematoloechus varioplexus.

\begin{tabular}{lcc}
\hline & \multicolumn{2}{c}{$\begin{array}{c}\text { No. infected/no. } \\
\text { exposed survivors }\end{array}$} \\
\cline { 2 - 3 } Experimental taxon & $\begin{array}{c}H . \\
\text { longiplexus }\end{array}$ & $\begin{array}{c}H . \\
\text { varioplexus }\end{array}$ \\
\hline $\begin{array}{c}\text { Insecta } \\
\text { Odonata: Anisoptera } \\
\quad \text { Libellula } \text { sp. }\end{array}$ & & \\
$\begin{array}{c}\text { Odonata: Zygoptera } \\
\text { Ischnura verticalis } \\
\text { Ephemeroptera } \\
\text { Baetis } \text { sp. }\end{array}$ & $2 / 10$ & $10 / 10$ \\
$\begin{array}{c}\text { Crustacea } \\
\text { Isopoda } \\
\text { Asellus } \text { intermedius }\end{array}$ & $6 / 10$ & $0 / 10$ \\
\hline
\end{tabular}

June 1995 from Nevens Pond, a stock tank runoff pond in Keith County, Nebraska (Nevens Quadrangle, SW 1/4, Sec. 2, T14N, R36W). Previous surveys have established that all life cycle stages of $H$. complexus and $H$. medioplexus are present in this pond, but no other species of Haematoloechus is present (S. D. Snyder, unpubl. obs.).

Arthropods were isolated from collected snails within $1 \mathrm{hr}$ of collection and necropsied within $72 \mathrm{hr}$. In anisopterans with dual species infections, $H$. complexus metacercariae were distinguished from $H$. medioplexus metacercariae by their location in the host's body. Metacercariae of $H$. medioplexus encyst only in the branchial basket, whereas metacercariae of $H$. complexus rarely encyst in this structure (Krull, 1933; Snyder and Janovy, 1994). Metacercariae in the branchial basket were recorded as $H$. medioplexus; metacercariae in other tissues were recorded as $H$. complexus.

\section{Statistical analysis}

Data from all cercarial attachment experiments were combined and analyzed by host taxa using analyses of variance. Calculations were completed using Field Stat (Clopton and Janovy, 1990). When ANOVA indicated a significant difference in attachment among parasite species, differences between species pairs were evaluated using Tukey's $w$ procedure (Steel and Torrie, 1980). To ensure that the results of the first and second attachment experiments were comparable, $t$-tests (Clopton and Janovy, 1990) were used to compare the number of $H$. complexus cercariae in each experiment attached to each experimental arthropod. All tests were conducted at the $\alpha=0.05$ level of significance.

\section{RESULTS}

\section{Host specificity of $\boldsymbol{H}$. longiplexus and $H$. varioplexus}

Metacercariae of $H$. longiplexus developed in both Libellula sp. and $I$. verticalis, although not all exposed odonates became infected (Table I). Haematoloechus varioplexus metacercariae were found in the branchial baskets of all 10 experimental libellulids but were not present in other experimental arthropods. In the $H$. complexus-positive control for host strain resistance, metacercariae developed in all 4 arthropod species. No metacercariae were observed in a $T_{0}$ or $T_{t}$ control group.

\section{Observations of cercarial behavior}

Distinct cercarial behavior patterns were observed among the 4 species of Haematoloechus studied. Cercariae of $H$. complexus stopped swimming upon contact with a host and began to crawl 

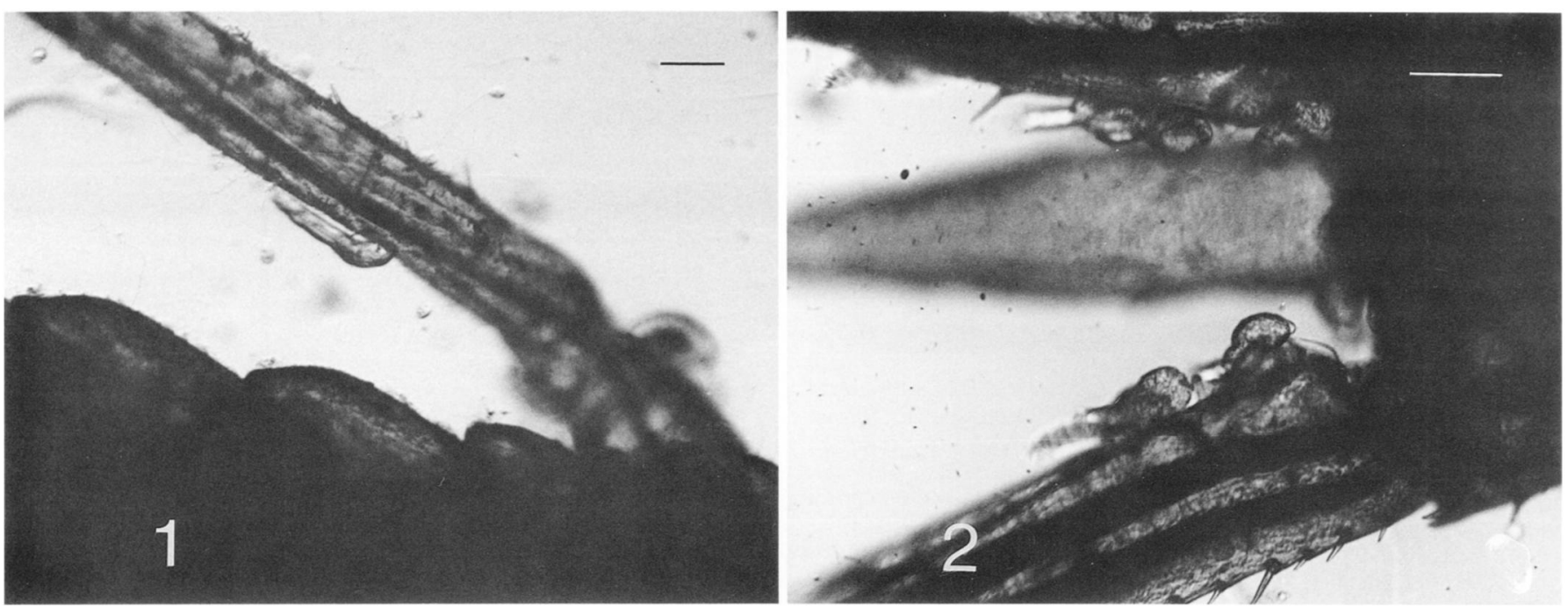

FIGURES 1, 2. Cercariae of Haematoloechus spp. attached to Ischnura verticalis. 1. Haematoloechus complexus cercaria attached to and crawling on a leg of I. verticalis. 2. Haematoloechus longiplexus cercariae aggregated on the caudal gills of I. verticalis. Bars correspond to $100 \mu \mathrm{m}$.

along the surface of the host body, probing it with their stylets (Fig. 1). Once cercariae encountered an intersegmental membrane, they often began to thrust the stylet into the membrane. Some $H$. complexus cercariae were observed to drop the tail, pierce the intersegmental membrane with the stylet, and enter the body of the arthropod through the resultant hole. The complete penetration process took over $30 \mathrm{~min}$.

The attachment behavior of $H$. longiplexus was similar to that of $H$. complexus. Cercariae of $H$. longiplexus often stopped swimming on contact with an experimental host and crawled along the surface of the host body. When in contact with $I$. verticalis, cercariae of $H$. longiplexus aggregated at the base of the naiad's caudal gills (Fig. 2). Many of these cercariae thrust their stylets into the membrane at the tip of the abdomen, penetrated the membrane, and entered the body of the naiad. The tails of the cercariae dropped off during the penetration process.

In contrast to $H$. complexus and $H$. longiplexus, cercariae of $H$. medioplexus encountering an experimental host were simply deflected and continued swimming. The behavior of cercariae of $H$. varioplexus was identical to that of $H$. medioplexus.

\section{Cercarial attachment experiments}

The mean number of attached cercariae (calculated across all experimental trials) was higher for $H$. longiplexus and $H$. complexus than for $H$. medioplexus and $H$. varioplexus. This pattern was true for all experimental host species (Table II). For example, an average of 19.6 and 14.0 cercariae of $H$. longiplexus and $H$. complexus, respectively, attached to $I$. verticalis experimentals. In contrast, an average of only 0.2 cercariae of both $H$. medioplexus and $H$. varioplexus attached to $I$. verticalis.

Analysis of variance showed no significant difference in the number of cercariae of $H$. complexus, $H$. longiplexus, $H$. medioplexus, and $H$. varioplexus attached to the control $\left(F_{3.21}=\right.$ 2.33, $P>0.05)$. A significant difference in attachment was present between cercariae attached to $A$. intermedius $\left(F_{3,21}=\right.$ 6.92, $P<0.05)$, $I$. verticalis $\left(F_{3,21}=101.47, P<0.05\right)$, and Libellula spp. $\left(F_{3,21}=13.80, P<0.05\right)$.
When the first and second attachment experiments were compared, a $t$-test showed no significant difference in the number of $H$. complexus cercariae attached to $I$. verticalis $(t=0.68$, $\mathrm{df}=8, P>0.05)$, A. intermedius $(t=2.07, \mathrm{df}=8, P>0.05)$, or Libellula spp. $(t=1.13, \mathrm{df}=8, P>0.05)$. Thus, results of both experiments can be considered directly comparable.

\section{Population structure of Haematoloechus}

The prevalence, relative density (mean number of parasites/ host), and mean intensity of $H$. complexus metacercariae in naturally infected arthropods are listed in Table III. Only arthropod species found in numbers of 4 or greater are listed. Haematoloechus medioplexus metacercariae were found only in the anisopteran odonate Libellula lydia, with 15 of 16 (94\%) hosts infected. The relative density was 4.56 metacercariae/ odonate and the mean intensity was 4.87 metacercariae/infected odonate.

\section{DISCUSSION}

This study demonstrates that differences in cercarial behavior can directly affect the number of host species available to closely related parasite species. Thus, the evolution of different patterns of cercarial behavior has led to different patterns of host specificity among members of the genus Haematoloechus.

Haematoloechus medioplexus and $H$. varioplexus cercariae are passive host invaders, not altering their behavior in response to contact with aquatic arthropods but continuing to swim throughout the water column. Cercariae of $H$. medioplexus and $H$. varioplexus must be drawn into the unique branchial basket respiratory apparatus of anisopterans, a phenomenon reported by Krull (1931). Once inside the branchial basket, cercariae are able to encyst and develop into metacercariae. In the present study, no metacercariae of $H$. varioplexus were found outside the branchial baskets of susceptible anisopterans. Metacercariae of $H$. medioplexus are also restricted to this region of the host (Snyder and Janovy, 1994). The inability of $H$. medioplexus and 
TABLE II. Mean number of Haematoloechus longiplexus, Haematoloechus complexus, Haematoloechus medioplexus, and Haematoloechus varioplexus cercariae attached to 3 experimentally exposed hosts and a silicone control.*

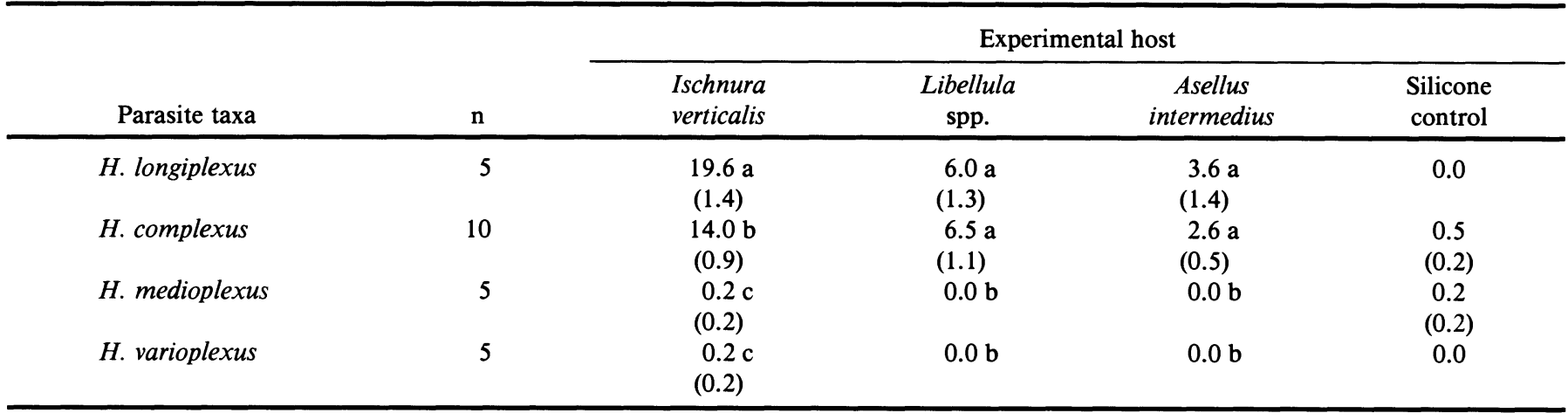

* Identical letters within a column indicate no significant difference between parasite attachment means within host type according to Tukey's $w$ procedure (Steel and Torrie, 1980). Number in parentheses equals SE.

$H$. varioplexus cercariae to attach and penetrate the exoskeleton of a potential host therefore restricts these parasites to development in anisopteran (dragonfly) odonate naiads (Table I; Snyder and Janovy, 1994).

The generalist nature of $H$. complexus within second intermediate hosts contrasts directly with the specialist nature of $H$. medioplexus and $H$. varioplexus. Metacercariae of $H$. complexus have been found experimentally to develop in 3 insect orders and 3 species of freshwater crustaceans (Snyder and Janovy, 1994). Natural infections reported in the present study add a fourth insect order (Coleoptera) and a fourth crustacean species (Hyalella azteca) to the list of second intermediate hosts for this species (Table III). The ability of $H$. complexus to develop in such a wide range of aquatic arthropods is directly linked to the behavior of the cercariae. Haematoloechus complexus cercariae are active host invaders. These cercariae stop upon contact with a potential host, attach to the arthropod, and are then able to penetrate the host at any intersegmental membrane. Cercariae of $H$. complexus also gain access to anisopteran hosts by being drawn into the branchial baskets of these insects (Krull, 1933), but this passive mode of entrance is not essential for $H$. complex$u$ s as it is for $H$. medioplexus and $H$. varioplexus.

Haematoloechus longiplexus occupies the middle of the continuum of second intermediate host specificity displayed by the species examined in this study. Metacercariae of this species are able to develop in zygopteran (damselfly) as well as anisopteran naiads (Table I; Krull, 1932). However, development does not appear to be possible in non-odonate second intermediate hosts. Cercariae of $H$. longiplexus stop swimming and attach upon contact with an aquatic arthropod but appear unable to penetrate an intersegmental membrane as can cercariae of $H$. complexus. Although $H$. longiplexus is an active host invader, the cercariae penetrate only zygopteran naiads, and then only at the base of the caudal gills. This site specificity apparently prevents $H$. longiplexus from parasitizing non-odonate aquatic arthropods. Given that the other 3 species examined in this study gain access to anisopteran odonates by being drawn into the branchial basket, it seems likely that $H$. longiplexus cercariae enter these insects in the same way.

It is clear that the cercariae of $H$. longiplexus and $H$. complex-

TABLE III. Population structure of Haematolechus complexus metacercariae in arthropods collected from Nevens Pond, Keith County, Nebraska.*

\begin{tabular}{|c|c|c|c|c|}
\hline \multicolumn{5}{|l|}{ Insecta } \\
\hline Libellula lydia & 16 & 56 & 4.94 & 8.78 \\
\hline \multicolumn{5}{|l|}{ Odonata: Zygoptera } \\
\hline Ischnura verticalis & 30 & 100 & 19.10 & 19.10 \\
\hline Baetis sp. & 30 & 0 & 0.00 & 0.00 \\
\hline Baetisca sp. & 13 & 69 & 1.20 & 1.77 \\
\hline \multicolumn{5}{|l|}{ Coleoptera } \\
\hline \multicolumn{5}{|l|}{ Hydrophilidae } \\
\hline Gen. sp., larvae & 4 & 75 & 0.75 & 1.00 \\
\hline \multicolumn{5}{|l|}{ Crustacea } \\
\hline
\end{tabular}

* Listed are prevalence, relative density (mean number of parasites/host), and mean intensity. 
us use the cercarial stylet to gain entry into some hosts. The role of the cercarial stylet of $H$. medioplexus and $H$. varioplexus is less obvious. The stylet length of the of $H$. complexus $(30.0 \mu \mathrm{m})$ is considerably longer than that of $H$. medioplexus $(17.5 \mu \mathrm{m})$, $H$. varioplexus $(19.9 \mu \mathrm{m})(\mathrm{Krull}, 1931,1933)$, and $H$. longiplexus $(18.2 \mu \mathrm{m})$ (S. D. Snyder, unpubl. obs.). Krull $(1930,1931)$ reported that metacercariae of $H$. medioplexus and $H$. varioplexus most commonly occur within the lamellae that comprise the anisopteran respiratory structure, indicating that cercariae of these species must penetrate the chitin that surrounds the lamellae. If this is the case, use of the stylet would seem the most obvious mechanism for penetration. Thus, a functional role of the stylet may be maintained in these passive host invaders.

Cercariae of both $H$. longiplexus and $H$. complexus attached to naiads of the damselfly $I$. verticalis in much higher numbers than to other experimental hosts (Table II). This difference may indicate that cercariae of these 2 species are more attracted to I. verticalis than to the isopod $A$. intermedius, the dragonflies Libellula spp., or the control. However, because of the differences in the size and opacity of the 3 experimental arthropods, it may be misleading to compare directly the number of attached cercariae across all experimental hosts. Ischnura verticalis used in these experiments were smaller and less opaque than Libellula spp. and less opaque than $A$. intermedius. Differences in experimental host opacity could have had an effect on our ability to count attached cercariae. Differences in experimental host size certainly altered cercarial encounter rates.

Alternatively, differences in cercarial attachment across experimental host taxa may indicate a preference of cercariae for damselfly hosts. Field data corroborate this conclusion. One hundred percent of $I$. verticalis examined from Nevens Pond were infected with $H$. complexus (Table III). Only $56 \%$ of $L$. lydia and $14 \%$ of $H$. azteca were infected. Although these results could indicate that $I$. verticalis occupies a microhabitat more conducive to infection with $H$. complexus than do the other arthropods, because of experimental results we conclude that cercariae are differentially attracted to different host species.

It is not known what cues, if any, $H$. complexus and $H$. longiplexus use to find their hosts. The maximum numbers of cercariae attached to an experimental host were $18 \mathrm{H}$. complexus and $24 \mathrm{H}$. longiplexus, both attached to $I$. verticalis. Even in these experimental cases, nearly half of the 40 experimental cercariae did not attach to the host. No cercariae appeared to seek a host actively. Cercariae often swam within fractions of a $\mathrm{mm}$ of the experimental arthropods without adjusting the pattern of swimming to make contact. Attachment, crawling, and penetrating behaviors were elicited only on host contact. It is possible that directed swimming was not observed because the small water volume in the depression slide and occasional arthropod movements prohibited the establishment of chemical gradients that might serve as cercarial cues. No report of random host location and penetration exists for cercariae that actively invade their hosts (Haas, 1994a).

Cercarial behavior in the presence of the silicone control supports the premise that cercariae of $H$. complexus and $H$. longiplexus do respond to cues of host origin. Upon encountering a live host, cercariae of these species were stimulated to attach and maintain contact, whereas those encountering the silicone control were not (Table II). The response of all 4 species of Haematoloechus to the silicone control suggests that the at- tachment stimulus is not touch as Clegg (1969) demonstrated for cercariae of Austrobilharzia terrigalensis. Cercariae of other trematode species attach in response to a wide variety of physical and chemical stimuli (Haas, 1994b).

Haas (1994b) referred to cercarial movement on a host that leads to an appropriate penetration site as directed creeping. The movement of cercariae of $H$. longiplexus toward the base of the caudal gills of $I$. verticalis appears to be an example of this phenomenon. The aggregation around the gills and penetration exclusively at the tip of the abdomen indicate the presence of a cue that leads $H$. longiplexus cercariae to this site. The fact that aggregation and penetration occur in close proximity to the host respiratory structures suggests that the release of dissolved gases may play a role in cercarial site-finding behavior. Cercariae of Isthmiophora melis are stimulated to attachment by dissolved $\mathrm{CO}_{2}$ and $\mathrm{H}_{2} \mathrm{CO}_{3} / \mathrm{HCO}_{3}{ }^{-}$(Motzel and Haas, 1985). Haematoloechus complexus cercariae do not aggregate around the gills but penetrate at any membranous site on the body of I. verticalis. This observation suggests that these cercariae do not respond to the same putative site identification cues as $H$. longiplexus.

Snyder and Janovy (1994) hypothesized that the generalist nature of $H$. complexus metacercariae would enable members of this species to be encountered by definitive hosts in greater numbers than metacercariae of the specialist $H$. medioplexus. Data from the current study support this idea. In Nevens Pond, $H$. complexus parasitizes at least 5 second intermediate hosts not parasitized by $H$. medioplexus (Table III). Although the numbers of host species infected and metacercariae present in this pond likely change over time, $H$. complexus clearly has more avenues into the diet of a frog than does $H$. medioplexus. These avenues are created by differences in cercarial behavior between the 2 species. No field data are available to indicate the transmission effects of the development of $H$. longiplexus in both dragonflies and damselflies. However, it is probable that $H$. longiplexus reaps the benefit of increased transmission opportunities in a manner similar to $H$. complexus.

Reports of the ability of other species of Haematoloechus to utilize non-anisopteran hosts indicate that disparate patterns of cercarial behavior are present worldwide. For example, Combes (1968) reported the successful experimental infection of plecopteran larvae with metacercariae of the European species Haematoloechus pyrenaicus. Thus, $H$. pyrenaicus may be a second intermediate host generalist like $H$. complexus because of an ability to penetrate intersegmental membranes. Alternatively, because $H$. pyrenaicus metacercariae were found only in association with the respiratory structures of plecopterans and anisopterans, this parasite may react, like $H$. longiplexus, to stimuli from a more restricted set of hosts.

The worldwide distribution of the genus Haematoloechus presents an ideal system to explore the range of cercarial behavior and resultant host specificity in parasites with a common evolutionary history. A comparative analysis, in concert with the construction of a phylogeny of the members of this genus, would address the evolutionary development of cercarial behavior. This model could be used to determine if patterns of cercarial behavior and host specificity are the result of a common ancestry or are independently derived examples of convergence. These results would provide insight into the nature of host specificity, 
the acquisition of new hosts over evolutionary time, and of the evolution of complex life cycles in general.

\section{ACKNOWLEDGMENTS}

The authors thank R. E. Clopton for his comments on an earlier version of this manuscript. We also thank Liz Snyder and Lyndon Ruhnke for assistance in the collection of specimens. The use of facilities at Cedar Point Biological Station is gratefully acknowledged. This study was supported, in part, by the Ashton C. Cuckler Fellowship to S.D.S.

\section{LITERATURE CITED}

Adema, C. M., D. F. Arguello II, S. A. Stricker, AND E. S. Loker. 1994. A time-lapse study of interactions between Echinostoma paraensei intramolluscan larval stages and adherent hemocytes from Biomphalaria glabrata and Helix aspersa. Journal of Parasitology 80: 719-727.

Bethel, W. M., AND J. C. Holmes. 1977. Increased vulnerability of amphipods to predation owing to altered behavior induced by larval acanthocephalans. Canadian Journal of Zoology 55: 110-115.

ClEGG, J. A. 1969. Skin penetration by cercariae of the bird schistosome Austrobilharzia terrigalensis: The stimulatory effect of cholesterol. Parasitology 59: 973-989.

Clopton, R. E., AND J. Janovy, JR. 1990. Field Stat. Version 1.0. Hotel Intestine, Lincoln, Nebraska.

COMBES, C. 1968. Biologie, écologie des cycles et biogéographie de digènes et monogènes d'amphibiens dans l'est des Pyrénées. Mémoires du Muséum National d'Histoire Naturelle 51: 1-195.

Dollfus, R. P., J. M. Doby, AND P. LAurent. 1960. Sur une xiphidiocercaire parasitant Limnaea trunculata (O. F. Müller) en hautesavoie et s'enkystant dans des larves de moustiques. Bulletin de la Societe Zoologique de France 85: 331-347.

HAAS, W. 1994a. Physiological analyses of host-finding behaviour in trematode cercariae: Adaptations for transmission success. Parasitology 109(Suppl.): S15-S29.

-. 1994b. Physiological analysis of cercarial behavior. Journal of Parasitology 78: 243-255.
, B. Haberl, G. Schmalfuss, and M. T. Khyyal. 1994. Schistosoma haematobium cercarial host-finding and host-recognition differs from that of $S$. mansoni. Journal of Parasitology 80: 345-353.

KENNEDY, M. J. 1981. A revision of the genus Haematoloechus Loos, 1899 (Trematoda: Haematoloechidae) from Canada and the United States. Canadian Journal of Zoology 59: 1836-1846.

KRULL, W. H. 1930. The life history of two North American frog lung flukes. Journal of Parasitology 16: 207-212.

- 1931. Life history studies on two frog lung flukes, Pneumonoeces medioplexus and Pneumobites parviplexus. Transactions of the American Microscopical Society 50: 215-277.

- 1932. Studies on the life history of Haematoloechus longiplexus (Stafford). Zoologischer Anzeiger 99: 231-239.

- 1933. Studies on the life history of a frog lung fluke, Haematoloechus complexus (Seely, 1906) Krull, n. comb. Zeitschrift für Parasitenkunde 6: 193-206.

Motzel, W., AND W. HAAS. 1985. Studies on the attachment response of Isthmiophora melis cercariae (Trematoda: Echinostomatidae). Zeitschrift für Parasitenkunde 71: 519-526.

Olsen, O. W. 1967. Animal parasites: Their biology and life cycles. Burgess Publishing Company, Minneapolis, Minnesota, $431 \mathrm{p}$.

REA, J. G., AND S. W. B. IRWIN. 1991. Behavioural responses of the cercariae of Cryptocotyle lingua (Digenea: Heterophyidae) to computer-controlled shadow sequences. Parasitology 103: 471-477. , AND —. 1992. The effects of computer-controlled shadow stimuli on the success of cercarial transmission by Cryptocotyle lingua (Digenea: Heterophyidae). Parasitology 105: 243-246.

Read, C. P., L. T. Douglas, AND J. E. Simmons, JR. 1959. Urea and osmotic properties of tapeworms from elasmobranchs. Experimental Parasitology 8: 58-75.

SNYDER, S. D., AND J. JANOVY, JR. 1994. Second intermediate hostspecificity of Haematoloechus complexus and Haematoloechus medioplexus (Digenea: Haematoloechidae). Journal of Parasitology 80: 1052-1055.

Steel, R. G. D., AND J. H. Torrie. 1980. Principles and procedures of statistics: A biometrical approach, 2nd ed. McGraw-Hill, Inc., New York, New York, p. 633. 